\title{
Davedan Show Di Amphi Theatre Nusa Dua Bali
}

\author{
Ni Made Ruastiti ${ }^{1}$, Ni Wayan Parmi ${ }^{2}$, Ni Nyoman Manik Suryani ${ }^{3}$, I Nyoman Sudiana ${ }^{4}$ \\ $123{ }^{4}$ Fakultas Seni Pertunjukan, Institut Seni Indonesia Denpasar \\ maderuastiti@isi-dps.ac.id
}

Artikel ini disusun dari hasil penelitian yang bertujuan untuk dapat memahami pertunjukan Davedan Show di Amphi Theatre Nusa Dua Bali. Penelitian ini dilakukan karena adanya ketimpangan antara asumsi dan kenyataan di lapangan. Pada umumnya wisatawan yang datang ke Bali hanya senang dan antusias menonton seni pertunjukan pariwisata berbasis seni budaya lokal saja. Tetapi kenyataan ini berbeda. Walaupun Davedan Show tidak dibangun dari seni budaya lokal saja, tetapi kenyataannya wisatawan sangat senang menonton pertunjukan tersebut. Pertanyaannya: bagaimanakah bentuk pertunjukan Davedan Show tersebut?; mengapa wisatawan senang menonton pertunjukan itu?; apa implikasinya bagi pelaku, masyarakat, dan industri pariwisata di Nusa Dua, Bali?. Penelitian ini menggunakan metode penelitian kualitatif, khususnya implementatif partisipatoris yang mengutamakan kerjasama antara periset dengan para informan terkait. Sumber data penelitian ini adalah pertunjukan Davedan itu sendiri, pihak manajemen, para penari, penonton, hasil-hasil penelitian yang telah ada sebelumnya. Seluruh data yang telah dikumpulkan dengan teknik observasi, wawancara, FGD, dan studi kepustakaan itu dianalisis secara kritis dengan menggunakan teori estetika postmodern, teori praktik, dan teori relasi kuasa pengetahuan. Hasil penelitian menunjukan bahwa: (1) Davedan Show disajikan dalam bentuk oratorium. Hal itu dapat dilihat dari cara penyajian, koreografi, dan iringan pertunjukannya. Davedan Show yang menampilkan tema Treasure of The Archipelago, membuka gerbang petualangan baru itu diiringi musik rekaman etnik Nusantara secara medley, berkelanjutan dengan struktur pertunjukan: seni budaya Bali, Sumatra, Sunda, Solo, Kalimantan, dan seni budaya Papua; (2) Davedan Show banyak diminati wisatawan manca negara karena penciptaan pertunjukan itu dilatari oleh ideologi pasar, ideologi estetika, dan ideologi budaya Nusantara; (3) Hingga kini Davedan Show berkembang secara berkelanjutan di Nusa Dua Bali karena berimplikasi positif pada ekonomi para pihak terkait, pengayaan bagi seni pertunjukan daerah setempat, dan identitas bagi kawasan wisata Nusa Dua, Bali.

Kata kunci: davedan show, seni budaya nusantara, amphi theatre nusa dua, bali

\section{Davedan Show At Amphi Theatre Nusa Dua Bali}

This article was compiled from the research results that aimed to understand the Davedan Show at Amphi Theater Nusa Dua, Bali. This research was conducted due to the imbalance between the assumption and the reality in real life. Generally, tourists visiting Bali are more excited and enthusiastic to watch the tourism performing arts that are based on local traditional art and culture. However, the reality is different. The questions are: how is the form of the Davedan show?; why do the tourists enjoy watching the show ?; what are the implications for the performer, the society, and the tourism industry in Nusa Dua, Bali?. This research applied qualitative research methods, especially the participative implementation that prioritized cooperation between the researchers and the related informants. The data sources of the research were the Davedan show, management, dancers, audiences, and similar research results produced by previous researchers. All data that had been collected by observation, interview, FGD, and literature study were then analyzed with aesthetic postmodern theory, theory of practice, and theory of power relationship. The results showed that: (1) Davedan Show was presented with the concept of a new presentation in the tourism performing arts in Bali. It could be seen from the material, the form, the way of presentation, and the management of the show. Davedan Show, presenting the theme of Treasure of the Archipelago and opening the new adventure gate, was accompanied by ethnic music recordings of the archipelago in a medley then continued with the performance structures of: Balinese, Sumatran, Sundanese, Solo, Borneo and Papuan art and culture; (2) Davedan Show attracted many foreign tourists because the show was based on the existence of market, aesthetic, and cultural ideologies of the archipelago; (3) Currently, Davedan Show has developed in Nusa Dua, Bali sustainably because of its positive implications to the economics aspect of the stakeholders, the enrichment of Balinese performing arts, and the identity of Nusa Dua tourism area of Bali.

Keywords: davedan show, art and culture of archipelago, amphi theatre nusa dua, bali.

Proses Review : 1 - 31 Maret 2018, Dinyatakan Lolos: 10 April 2018 doi: dx.doi.org/10.31091/mudra.v33i2.365




\section{PENDAHULUAN}

Davedan Show adalah sebuah seni pertunjukan pariwisata yang dibangun dari seni budaya Nusantara, disajikan dengan teknik modern dalam bentuk oratorium dengan menggunakan dialog bahasa Inggis. Devdan show itu sendiri berasal dari bahasa Sansekerta yaitu Deva dan Dhana yang mengandung arti berkah Tuhan. Seni budaya Nusantara yang dimaknai produser Devdan Show bernama Liauw Suparsono sebagai sebuah berkah, potensi budaya unggul yang dikembangkan menjadi sumberdaya ekonomi bagi masyarakat di Bali yang dominan dikenal memiliki keterampilan sebagai seniman tari dan bisa menabuh gamelan yang mumpuni.

Atas gagasan dari Liauw Suparsono pada tahun 2011 Davedan Show diciptakan dengan menampilkan tema Treasure of The Archipelago yang berarti melihat berbagai kekayaan seni budaya di Indonesia. Alvin dan Heidi Tofffler (2002), menyetarakan tindakan tersebut dengan "terbentuknya peradaban baru" dalam sebuah masyarakat. Seni pertunjukan pariwisata yang disajikan secara regular setiap hari senin, rabu, dan jumat di Amphi Theatre Bali Nusa Dua itu tampak sangat diminati wisatawan manca negara.

Artikel ini disusun dari hasil penelitian yang bertujuan untuk dapat mengetahui dan memahami pertunjukan Davedan Show di Amphi Theatre Nusa Dua, Bali. Penelitian ini dilakukan karena adanya ketimpangan antara asumsi dan kenyataan di lapangan. Semestinya wisatawan yang datang ke Bali hanya senang dan antusias menonton seni-seni pertunjukan pariwisata berbasis seni budaya Bali saja. Namun kenyataannya ini berbeda. Walaupun Davedan Show yang sering disajikan untuk pariwisata di Amphi Theatre Nusa Dua Bali tidak hanya dibangun dari seni budaya Bali tetapi kenyataannya wisatawan sangat senang menonton pertunjukan tersebut. Hal itu menimbulkan berbagai pertanyaan, antara lain bagaimana bentuk pertunjukan Davedan Show tersebut, mengapa wisatawan senang menonton pertunjukan tersebut, dan apa implikasi pertunjukan itu bagi pelaku dan industri pariwisata di Nusa Dua Bali.

Pulau Bali merupakan objek pariwisata yang sangat terkenal dengan keunikan budayanya. Budaya Bali yang unik telah lama diminati wisatawan baik dalam maupun luar negeri. Dengan diminatinya seni buadaya Bali yang bernuansa religius itu maka banyak masyarakat daerah ini menyajikan seni pertunjukan pariwisata berbasis seni budaya daerah setempat. Hal itu dapat dilihat dari banyaknya tari-tarian yang awalnya bersifat sakral kemudian dikemas dan disajikan untuk pariwisata. Seperti misalnya tari Sang Hyang Jaran dikemas menjadi Cak and Fire dance, tari Sang Hyang Dedari dikemas menjadi tari Sang Hyang Legong untuk pariwisata, Adegan Ngunying (menusukan keris di dada) disajikan dalam pertunjukan Barong dang Kriss dance, dan lain sebagainya. Pesatnya perkembangan industri pariwisata secara tidak langsung telah mempengaruhi seni pertunjukan di Bali (Ruastiti, 2005; Picard, 2006).

Spillane (1987) mengungkapkan bahwa industri pariwisata secara tidak langsung memberikan peran dalam perubahan budaya baik itu positif maupun negatif. Interaksi antara masyarakat Bali dengan industri pariwisata secara tidak disadari telah mengakibatkan terjadinya perubahan pada segala aspek kehidupan masyarakat setempat. Ruastiti (2010) mengatakan bahwa perubahan kebudayaan masyarakat Bali karena pengaruh pariwisata dapat dilihat pada sikap dan orientasi masyarakatnya kini dalam mengembangkan sumberdaya yang dimiliki. Seperti misalnya dalam memilih profesi, menciptakan produk, lapangan pekerjaan, dan lain sebagainya. Berbagai jenis dan produk pariwisata baru banyak diciptakan untuk menyikapi peluang pasar, antara lain wisata budaya, wisata religi, wisata spa, wisata kuliner, wisata hiking, desa wisata, agro wisata, dan lain sebagainya.

Di Bali banyak terdapat seni pertunjukan pariwisata baru. seperti misalnya pertunjukan Bali Agung di Taman Bali Safari, Gianyar, Sexi Dancer di kapal-kapal pesiar yang berlabuh di DesaTanjung Benoa, Badung, Fire Dance di hotel-hotel kawasan wisata Nusa Dua, dan Davedan Show di Amphi Theatre Nusa Dua, Bali. Munculnya berbagai jenis wisata baru juga diiringi munculnya berbagai jenis seni pertunjukan baru untuk pariwisata. Beberapa di antaranya adalah munculnya pertunjukan Bali Agung sebagai daya tarik wisata berkunjung ke kebun binatang di Bali Safari, Gianyar. Menjamurnya Tari Api atau Fire Dance untuk memeriahkan acara dinner di daerah kawasan wisata Nusa Dua. Munculnya Sexi dancer untuk memeriahkan acara dinner di atas kapal pesiar yang sedang berlabuh di teluk Benoa, Badung, dan munculnya Davedan Show di Amphi Theatre Nusa Dua untuk menghibur wisatawan yang menginap di daerah kawasan wisata Nusa Dua, Bali. Hal senada juga terungkap dari hasil pengamatan yang dilakukan di Bali oleh Michael Picard (1992: 10)

Pertunjukkan Devdan Show di Bali Nusa Dua Theatre belakangan ini menjadi tajuk perbincangan hangat di kalangan pariwisata. Davedan Show yang menampilkan seni budaya daerah Bali, Sumatera, Jawa, Kalimantan dan Papua itu dikemas menjadi sebuah seni pertunjukan pariwisata yang disajikan dalam bentuk oratorium berbahasa Inggis dengan durasi 90 menit. Devdan Show mengingatkan akan adanya Bhineka Tunggal Ika, keanekaragaman budaya Nusantara yang disajikan di atas panggung megah berteknologi modern. Para penonton dibuat kagum atas teknik penyajian seni pertunjukan pariwisata tersebut. Berbagai seni budaya Nusantara yang disajikan secara meadley itu dikolaborasikan dengan adegan magic dance dan akrobatik couple yang menari melayang-layang di udara dengan teknik yang sangat memukau. Sebagai sebuah seni pertunjukan pariwisata, Davedan Show yang digelar dalam 
gedung theatre berkapasitas 700 kursi itu mampu mematahkan stigma bahwa seni pertunjukan pariwisata tidak berkualitas, disajikan asal-asalan, tanpa isi, murah, dan lain sebagainya.

\section{METODE PENELITIAN}

Penelitian ini dilakukan dengan menggunakan metode penelitian kualitatif, khususnya implementatif partisipatoris yang mengutamakan kerjasama antara periset dengan para informan terkait. Sumber data primer penelitian ini adalah pertunjukan Davedan itu sendiri, para informan terkait baik penari, pihak management, maupun para penonton pertunjukan tersebut. Sementara sumber data sekunder penelitian ini adalah hasil-hasil penelitian sejenis yang telah dihasilkan para periset sebelumnya. Seluruh data yang telah dikumpulkan dengan teknik observasi, wawancara, dan studi kepustakaan itu dianalisis menggunakan teori dekonstruksi, teori estetika postmodern, dan teori relasi kuasa pengetahuan.

\section{BENTUK PERTUNJUKAN DAVEDAN SHOW}

Sebagai sebuah seni pertunjukan pariwisata baru, Davedan Show disajikan dengan gagasan, konsep, dan cara penyajian baru yang berbeda dibandingkan dengan seni-seni pertunjukan pariwisata di Bali pada umumnya. Davedan Show yang menampilkan tema treasure of the archipelago itu disajikan dalam bentuk oratorium dengan menggunakan dialog bahasa Inggis, diiringi musik-musik rekaman etnik Nusantara. Liauw Suparsono selaku Produser Devdan Show menampilkan berbagai seni budaya Nusantara dengan konsep modern dengan tujuan agar seni budaya tradisional Nusantara dapat diperkenalkan kepada wisatawan sebagaimana theatre mereka di Barat.

Pihak manajemen melibatkan para pihak terkait yang mumpuni dalam bidangnya masing-masing, seperti Jeffrey Hall sebagai stage director, Jerry Snell membidangi artistic director, Axel Morgenthaler selaku artistic guide dan lighting designer, Bimo Wiwohatmo selaku choreographer, Henry Nelwan khusus membidangi hal-hal yng berkaitan dengan special effect dan illusion desaigner. Yoyon Suryono sebagai technical consultant, Jacque Lesvaques membidangi atau selaku lighting programmer, Kinting Handoko selaku costume \& make up desaigner. Dalam hal perancangan desain kostum tarian-tarian akrobatik (acrobatic costume designer) ditangani oleh Alvin Ariwibowo. Sementara sebagai compuser sekaligus musical director pertunjukannya adalah Joko Potong dan Erwin J. Khrisnanda, untuk urusan yang berkaitan dengan interactive projection desaigner ditangani oleh Hariadi, dan technical director pertunjukannya adalah Gunawan dan Dimas.

Davedan Show disajikan secara medley, berkelanjutan dengan struktur pertunjukan: seni budaya Bali, Sumatra,
Sunda, Solo, Kalimantan, dan seni budaya Papua. Pertunjukan Davedan Show yang disajikan di atas panggung procenium yang megah dengan dilengkapi lighting, sound system berteknologi tinggi tampak menyatu dengan budaya Nusantara. Animo wisatawan dalam menonton seni pertunjukan itu dapat dilihat dari penuhnya gedung Amphi Theatre yang berkapasitas 700 seat itu di setiap pertunjukan Davedan dilaksanakan.

Rekrutmen penaripun dilakukan secara profesional melalui proses audisi. Dalam audisi tersebut para peminat diseleksi kemampuan teknisnya dalam menarikan tari-tarian tradisional Nusantara, menarikan tari-tarian modern, dan wawasan tentang seni budaya Nusantara. Bimo Wiwohatmo selaku koreografi Devdan Show mengatakan bahwa seni budaya Nusantara yang ditampilkan dalam pertunjukan tersebut merupakan pengembangan dari bentuk aslinya. Begitupula yang dikemukakan oleh direktur teknikal pertunjukan Devdan Show yang bernama Dimas bahwa unsur-unsur penunjang pentas baik tata rias busana maupun properti pertunjukan yang digunakan adalah pengembangan bentuk seni-seni budaya unggul dari masing-masing daerah yang bersangkutan. Berbagai unsur seni budaya Nusantara yang menonjol diidentifikasi, dikembangkan menjadi seni pertunjukan pariwisata baru dengan struktur pertunjukan terdiri atas seni budaya Bali dengan simbol udeng (ikat kepala busana adat laki-laki di Bali), seni budaya Sumatra dengan simbol kain tenun songketnya, seni budaya Sunda dengan simbol keris, seni budaya Jawa dengan simbol wayang, seni budaya Dayak dengan simbol terompet kerang, dan seni budaya Papua dengan simbol koteka. Berbagai bentuk seni pertunjukan itu menjadi bingkai etnoestetika yang terdapat di masing-masing etnik di Indonesia (Chan, 2014).

Pertunjukan Davedan dimulai dari kisah dua orang anak kecil yang turut serta dalam sebuah rombongan wisatawan yang sedang berlibur dan tour di Bali dipandu oleh seorang guide. Rasa bosan anak-anak itu dengan perjalanan tournya itu membuat mereka memilih alternatif lain dengan memisahkan diri dari rombongan tour tersebut. Mereka berjalan-jalan menyusuri alam kemudian di atas bebukitan dalam perjalan itu mereka menemukan sebuah peti berisi harta karun. Dalam peti itu berisi benda-benda pusaka, simbol-simbol budaya daerah Nusantara, antara lain udeng, kain tenun songket, pecut, keris, wayang, terompet kerang, dan koteka. Satu-persatu benda-benda pusaka itu diambil dari dalam peti kemudian mereka ceritrakan fungsi serta makna setiap benda-benda pusaka yang ditemukan itu melalui pertunjukan tari.

Pertama-tama pertunjukan Davedan Show dimulai dari menggambarkan fungsi dan makna udeng bagi kehidupan masyarakat di Bali. Udeng adalah ikat kepala untuk perlengkapan busana adat kaum laki-laki di Bali. Untuk menggambarkan seni budaya daerah Bali ditampilkan tari Cak beserta kehidupan masyarakatnya yang religius. 
Sementara untuk menggambarkan kesenian daerah tersebut ditampilkan Tari Cak. Tari Cak dalam pertunjukan Devdan Show mengisahkan tentang peperangan antara kekuatan baik dengan kekuatan buruk. Masing-masing kekuatan baik yang dimiliki Rama maupun kekuatan buruk dari Rahwana bertempur. Hal itu disimbolkan dengan menyemburnya api di sekeliling stage seolah-olah membakar stage dan para penari Cak yang berada di sekeliling Rama. Atas kesaktian Rama, kobaran api yang menyala sangat tinggi itupun mampu dipadamkan Rama. Teknik menari para pelaku yang ditunjang property pertunjukan berteknologi modern seakan mampu menciptakan seni pertunjukan pariwisata itu mendekati realitas. Tari kecak yang ditarikan oleh 20 orang penari terdiri atas 13 penari laki-laki, 7 orang penari perempuan, dan 1 orang penari berperan sebagai Rama itu disajikan sangat dinamis. Gerakan tubuh penari merebahkan diri ke samping kanan, kiri, depan dan ke belakang dilakukan secara simetris dan kontras. Para penari yang bergerak secara full power sambil mengucapkan "cak - cak - cak - cak - cak" itu semakin hidup ditunjang linghting, sound system, dan panggung berteknologi canggih. Tari Cak dalam Davedan Show semakin memukau ditunjang oleh tata rias dan costum yang ditata oleh costume dan make up designer kondang bernama Kinting Handoko. Penari pria menggunakan udeng, badong, selendang, dan kain kotak--kotak. Sementara para penari Cak perempuan menggunakan kain kotak-kotak, selendang, dan tata rambut digelung. Pertunjukan tari Cak itupun semakin hidup karena ditunjang tata lampu yang profesioanl, menggunakan 64 moving light yang ditata oleh lighting programmer bernama Jacque Lesvaques.

Setelah pertunjukan seni budaya Bali. Anak-anak pemburu harta karun itupun menunjukkan temuannya yang terdapat dalam kotak kembali, yaitu berupa kain tenun dari daerah Sumatra. Kain tenun merupakan salah satu simbol budaya khas daerah Sumatra. Kain tenun adalah tekstil tradisional yang dikerjakan dengan tangan sangat indah karena bauran warna emas yang dikerjakan dengan pola tak berujung. Kain tenun Sumatra dikenal dengan nama songket. Pada abad ke-7 yaitu ketika masa keemasan Kerajaan Sriwijaya Raya di Palembang, kain songket merupakan barang yang sangat berharga.. Dalam bahasa Melayu, Songket yang berasal dari bahasa Sansekerta itu memiliki arti menenun. Songket dibuat dengan tangan dengan perangkat tenun khusus. Tari tenun dalam pertunjukkan Devdan Show disajikan untuk menunjukkan budaya khas Sumatra. Menarik untuk disimak karena tradisi menenun yang merupakan unsur budaya tradisional daerah setempat mampu divisualisasikan dengan teknik dan ragam gerak modern menyerupai teknik tari akrobat. Di tegah-tengah kegiatan para gadis menenun kain songket dari salah satu sisi stage muncul tari tradisional khas Sumatra yaitu Tari Saman. Diiringi musik rebana mereka menari sambil bernyanyi saling bersahut-sahutan. Sementara di sisi lain juga muncul beberapa penari yang berperan sebagai penjual sayur, buah-buahan, tembikar yang menggambarkan kehidupan pasar tradisional daerah tersebut. Dilatari kehidupan sosial budaya daerah Sumatra, kemudian muncul sekelompok penari pencak silat. Dengan teknik tari yang sangat bagus, para penari yang dimaknai sebagai para prajurit kerajaan Sriwijaya menari seolah saling memperlihatkan kepiawaiannya mempermainkan cambuk. Sementara di sisi lain juga terdapat sekelompok penari yang asyik bermain sulap khas daerah tersebut. Pada adegan selanjutnya ditampilkan tari bernuansa religius yakni tari Hujan. Masyarakat setempat memiliki keyakinan bahwa agar pertanian mereka berhasil, maka pada hari-hari tertentu mereka melakukan upacara ritual dengan mempersembahkan tari hujan yang diiringi nyanyi-nyanyian dan musik rebana. Persembahan seni budaya Sumatra ditutup dengan Tari Akrobatik Bendera yang ditarikan oleh serang penari laki-laki menari akrobat udara sambil menggantung di kain yang telah diikat tanpa menggunakan tali pengaman.

Adegan selanjutnya adalah ditemukannya cendera mata khas daerah Jawa yaitu keris. Keris merupakan senjata khas Jawa yang selain berfungsi sebagai senjata juga merupakan identitas budaya masyarakat yang menyimbolkan status sosial, kejantanan, kegagahan para prajurit dari kerajaan Solo. Untuk menggambarkan seni budaya Solo dihadirkan rumah Joglo, rumah adat Jawa yang seluruhnya terbuat dari kayu dan memiliki filosofi khusus sesuai dengan pembagian tata ruangnya. Di depan rumah Joglo tersebut menari sekelompok penari laki-laki yang menggambarkan para prajurit kerajaan Solo yang gagah. Selain ditampilkan para prajurit kerajaan yang gagah dengan kerisnya di pinggang, pada saat itu juga ditampilkan Tari Bedhaya. Tari Bedhaya dimaknai sebagai tari suci bagi kalangan Kerajaan, istana Raja. Pada zaman kerajaan, Tari Bedhaya ditarikan oleh para gadis berjumlah 7 hingga 9 orang penari di mana salah seorang penari inti itu sebelum menari harus mengikuti upacara ritual khusus. Selain Tari Prajurit, Tari Bedhaya, untuk menggambarkan budaya Jawa juga ditampilkan kesenian Wayang Kulit. Tari Bedhaya yang dipadukan dengan adegan dalang memainkan wayang kulit ini ditutup dengan munculnya Tari Hip-Hop. Sebagai simbol keceriaan para generasi muda di Jawa yang sedang berusaha mencari identitas diri. Keceriaan mereka menari sambil berolah raga itu dimaknai masyarakat setempat sebagai kreativitas seni yang mampu memberi angin segar bagi perkembangan kesenian tradisional di daerah tersebut.

Pada bagian keempat adalah ditemukannya unsur budaya, cendera mata dari daerah Kalimantan yakni Terompet. Terompet kerang adalah salah satu alat musik tradisional khas daerah setempat yang keberadaannya ketika zaman kerajaan merukapan benda sakral, simbol perintah raja. Penduduk asli daerah setempat adalah suku Dayak. Gadis Dayak dikenal memiliki paras cantik. Sementara para pemudanya dikenal gagah. Kehidupan mereka di zaman dahulu kala di hutan divisualisasikan dengan tari balet romantis yang melayang-layang di udara. Dikisahkan bahwa 
di desa Dayak yang sunyi terdapat sepasang sejoli sedang memadu kasih. Kepiawaian para penari menari melayang-layang diudara banyak mengundang decak kagum penonton. Adegan romantis suku Dayak yang sedang memadu kasih itu ditutup dengan munculnya Tari Hujan. Kalimantan sangat dikenal dengan kehidupan masyarakatnya yang hidup di pinggir sungai. Bahkan hingga kini mereka masih menggunakan sungai sebagai sarana transportasi. Oleh sebab itu pada adegan budaya Kalimantan ini juga ditampilkan Tari Air, yang dimaknai sebagai kehidupan masyarakat dayak yang sangat akrab dengan sungai. Di sisi lain juga ditampilkan kehidupan sekelompok nelayan yang sedang menangkap ikan. Dikisahkan bahwa pada suatu hari para nelayan itu memperoleh tangkapan ikan yang ajaib. Salah seorang warga bahkan mengalami nasib naas ketika berusaha menjinakkan ikan tersebut. Oleh sebab itu, masyarakat setempat hingga kini memiliki keyakinan bahwa agar tidak mengalami hal-hal yang tidak diinginkan mereka melakukan upacara ritual larung laut. Adegan budaya khas Kalimantan itu ditutup oleh adegan tari monyet sebagai simbol bahwa Kalimantan yang hingga kini masih dominan terdiri dari hutan lindung melestarikan berbagai satwa langkanya termasuk monyet dan orang hutan.

Pertunjukan selanjutnya adalah ditemukannya unsur budaya Papua yaitu Koteka. Koteka merupakan pakian asli laki-laki Papua. Koteka terbuat dari kulit labu air. Kata Koteka berasal dari suku Paniai yang berarti pakaian yang digunakan untuk menutupi kemaluan laki-laki. Untuk melengkapi budaya papua disajikan Tari Asmat. Tari Asmat dibangun dari ragam gerak yang sangat dinamis baik dari gerakan kaki, tangan dan gerakan akrobatik. Tari Asmat disajikan dengan struktur pertunjukan dimulai dari pembukaan yang mengisahkan penduduk suku Asmat yang sedang mengontrol pertaniannya, menaiki rakit berlayar di sungai berlatarkan rumah Honai. Para penari Asmat yang terdiri dari 17 orang penari laki-laki dan perempuan. Pada sudut belakang terdapat 2 orang pemain alat musik Tifa. Mereka berjingkrak-jingkrak menggunakan gerakan kaki yang khas Tari Asmat. Penyajian Tari Papua ini diakhiri oleh munculnya sekelompok penari laki-laki dan perempuan berjumlah 9 orang membawa sejata tombak dan busur. Dalam tarian itu mereka memperlihatkan kepiawaiannya memburu binatang dengan memanah maupun menombak binatang buruannya.

Di belakang tari-tarian yang ditampilkan terdapat properti rumah khas suku Papua yaitu Honai. Honai adalah rumah tradisional suku Papua. Rumah tinggal dengan atap berbentuk kerucut yang atapnya terbuat dari jerami. Bangunan tersebut tergolong pendek. Menurut mereka konstruksi itu dibuat sedemikian rupa agar para penghuni rumah tersebut tidak kedinginan. Hal itu disebabkan karena Suku Asmat bertempat tinggal di daerah penguinungan. Untuk melengkapi visualisasi budaya suku Asmat disajikan Tari Papua. Tari Papua ini ditarikan oleh sekelompok penari laki-laki berbusana rumbai-rumbai dengan hiasan kepala bulu burung. Selain Tari Papua, juga ditampilkan Tari Tifa. Tifa adalah alat musik perkusi dari Papua dan Maluku. Instrumen itu memiliki bentuk yang mirip dengan drum, dimainkan dengan dipukul menggunakan kedua tangn secara bergantian. Tifa sendiri terbuat dari kayu berongga. Salah satunya berongga dan pada ujung-ujungnya ditutupi kulit membentang. Tifa biasanya dimainkan untuk mengiringi tari tradisional seperti tari perang dan upacara penting di Papua. Adegan budaya Asmat ini diakhiri oleh keluarnya sekelompok penari laki-laki diiringi musik Tifa sebagai simbol keperkasaan laki-laki Papua.

\section{IDEOLOGI DI BALIK PERTUNJUKAN DAVEDAN SHOW}

Hingga kini pertunjukan Davedan Show terus berkembang secara berlanjutan di Nusa Dua, Bali. Hal itu karena keberadaannya dilatari oleh adanya ideologi pasar, ideologi estetika, dan ideologi budaya Nusantara. Ideologi merupakan abstraksi perjuangan para agensi pada tatanan suprastruktur. Ideologi dapat diartikan sebagai pengetahuan, pemahaman, gagasan, ide atau ajaran tentang pengertian-pengertian dasar yang benar. Aiken (2009) menyatakan bahwa ideologi merupakan intisari visi, keyakinan yang secara intangibel telah berkontribusi signifikan terhadap tindakan yang dilakukan.

Sebagai sebuah seni pertunjukan pariwisata baru, Davedan Show sangat diminati pasar. Hal itu dapat dilihat dari ramai dan antusiasnya wisatawan menonton pertunjukan tersebut. Suasana itu merupakan spirit sosial, respon pasar terhadap pertunjukan Davedan Show sebagai produk pariwisata baru di Nusa Dua, Bali. Pasar bebas telah memberi peluang ekonomi bagi masyarakat setempat untuk mengembangkan sumberdaya dan potensi yang dimiliki. Kemajuan ilmu pengetahuan dan teknologi informasi di tengah-tengah persaingan pasar bebas di era global membuka banyak peluang sekaligus tantangan. Di satu sisi, kondisi ini bisa meningkatkan iklim kompetitif dari segi kualitas dan harga komoditi. Sementara di sisi lain, hal ini dapat sebagai ancaman bagi setiap produk yang sedang ditawarkan di pasar. Peluang global dan potensi berkesenian masyarakat di daerah kawasan wisata Nusa Dua merupakan dua faktor utama dari pertunjukan Davedan Show. Berbagai potensi sumber daya dalam berkesenian terbaik dituangkan dalam media gerak yang ditata indah menjadi sebuah komoditi pariwisata. Pertunjukan Davedan Show dirancang para pihak terkait sebagai sumber ekonomi untuk mendapatkan keuntungan atas kunjungan wisatawan ke Bali. Begitu kuatnya makna estetika dari pertunjukan Davedan Show itu terpatri pada setiap masyarakat di daerah kawasan wisata Nusa Dua sehingga pertunjukan itu memiliki citra tersendiri dalam seni pertunjukan pariwisata Bali.

Sebagai komoditi pariwisata baru di daerah tersebut Davedan Show bermakna nilai lebih bagi masyarakat setempat 
dan para pihak terkait. Keberlangsungan Davedan Show sebagai seni pertunjukan pariwisata baru di Nusa Dua, Bali tampak telah dapat meningkatkan kesejahteraan masyarakat terkait sebagai pelaku pertunjukan tersebut. Dengan menjadi penari Davedan Show mereka memperoleh masukan finansial. Terpilihnya sebagai pelaku dalam pertunjukan itu dianggap telah menjadi sumber ekonomi bagi keluarga mereka. Kesibukan masyarakat di daerah tersebut berkutat dengan urusan pekerjaan domestik dan aktivitas profesi mereka masing-masing di ruang publik tidak membuat mereka absen dari momen pertunjukan tersebut. Hal itu menandakan bahwa pertujukan Davedan Show diperlukan untuk peningkatan kualitas hidupnya saat ini. Davedan Show yang dipentaskan secara reguler setiap hari senin, rabu, dan jumat di Amphi Theatre berdampak positif bagi pelaku di daerah kawasan wisata Nusa Dua.

Pertunjukan Davedan Show yang dibangun dari berbagai potensi seni budaya Nusantara tampak harmonis disajikan dalam konsep estetika postmodern. Hal itu dapat dilihat dari tata cara penyajiannya, stage, lighting, dekorasi panggung, dan properti yang digunakan. Seni pertunjukan pariwisata memiliki konsep tersendiri yang tentu saja tidak sama dengan konsep seni pertunjukan tradisional masing-masing daerah Nusantara. Pengetahuan yang berintikan kaidah-kaidah penyajian seni pertunjukan pariwisata itu dapat dilihat dari bentuk tampilan, struktur, tata rias busana, lakon, maupun teknik pelaku dalam menyajikan pertunjukan tersebut. Seluruh komponen pertunjukan disusun berdasarkan kaidah-kaidah, konsep seni pertunjukan pariwisata yang berorientasi pada ekonomi. Hal itu sudah dapat dilihat dari perancangan, tampilan pertunjukan yang dibuat lebih menarik, atraktif, meriah, dan mengandung unsur kebaruan. Davedan Show disajikan dengan konsep yang baru dan berbeda dengan seni pertunjukan pariwisata pada umumnya.

Koreografi Davedan Show yang terdiri atas seni budaya Nusantara dapat dimaknai sebagai satu kesatuan yang utuh tentang keragaman budaya. Hal itu dapat dilihat dari tata rias busana para penari yang ditata sesuai dengan identitas budaya daerah maing-masing namun ditata secara modern. Berbagai busana daerah seperti hiasan kepala, kostum dan perangkat lainnya mampu menginformasikan simbol budaya masing-masing daerah di Indonesia walaupun seluruhnya itu sudah ditata secara modern. Hal itu tentu terungkap melalui perpaduan warna tata rias busana, properti, tata lampu pertunjukan tersebut. Pertunjukan Davedan Show yang diiringi oleh musik enik itu memiliki kekuatan dan identitas tersendiri. Secara dekonstruktif, Davedan Show merupakan praktek estetis yang melibatkan relasi kuasa sang pemilik modal, pencipta para penari dan selera pasar. Konstruksi para pihak tersebut dapat dilihat mulai dari proses penciptaan, kemudian berdampak terhadap bentukan citra positif secara kolektif di mana pada setiap fase itu tidak saja muncul keindahan sebagai sebuah makna tunggal yang murni, melainkan juga mun- cul nilai jual yang dipengaruhi oleh kepentingan pasar dan identitas budaya secara ideologis. Dalam masyarakat kapitalis, seni diubah menjadi komoditas dan diselubungi ideologi (Eagleton dalam Atmadja, 2010, 135-136)

Davedan Show dapat bermakna budaya Nusantara. Artinya bahwa para penari yang tampil dalam pertunjukan pariwisata itu berupaya mempromosikan budaya $\mathrm{Nu}$ santara. Pertunjukan Davedan Show dalam konteks itu dianggap elemental budaya yang merupakan kebanggan masing-masing suku di Indinesia. Oleh sebab itu, secara tidak langsung pertunjukan Davedan Show menguntungkan bagi pelestarian nilai-nilai budaya Nusantara. Melalui aktivitas pariwisata itu, secara tidak langsung unsur-unsur budaya Nusantara terajarkan kepada para penari. Proses pelestarian budaya itu berlangsung secara berkesinambungan. Para penari mendapatkan pelatihan dan pengetahuan tentang adat-istiadat masing-masing daerah Nusantara yang ditampilkan. Melalui Davedan Show mereka memperoleh keterampilan menari yang secara tidak langsung berimplikasi pada penguatan karakter budaya daerah di Indonesia.

Masyarakat terkait di daerah kawasan wisata Nusa Dua memandang bahwa Davedan Show sebagai pertunjukan yang bermanfaat bagi pemenuhan kebutuhan hidupnya. Melalui sikap mereka dapat diketahui bahwa seni pertunjukan pariwisata baru itu diterima dengan baik karena dianggap sesuai dengan kaidah, norma budaya setempat. Artinya bahwa keberadaan pertunjukan Davedan Show yang hingga kini berkembang secara berkelanjutan di daerah kawasan Nusa Dua dianggap sesuai dengan nilainilai budaya di daerah tersebut. Para pihak terkait bahkan memandang bahwa pertunjukan Davedan Show memiliki arti penting dalam enkulturasi budaya Nusantara di daerah tersebut. Hal itu dikarenakan Davedan Show berkontribusi dalam memupuk integrasi, komunikasi, penyatuan pemahaman kolektif tentang budaya Nusantara melalui industri pariwisata di Bali.

\section{IMPLIKASI PERTUNJUKAN DAVEDAN SHOW}

Hingga kini Davedan Show berkembang secara berkelanjutan sebagai daya tarik kawasan wisata Nusa Dua, Bali karena berimplikasi pada ekonomi para pihak terkait, pengayaan bagi seni pertunjukan daerah Bali, dan identitas bagi kawasan wisata Nusa Dua, Bali.

Selain dapat memajukan nama daerah, Davedan Show berimplikasi bagi kehidupan masyarakat terkait di Nusa Dua, Bali. Melalui keberadaan pertunjukan Davedan Show dapat dibaca gejala perubahan budaya masyarakat di Nusa Dua. Piliang (2004:112-114) mengemukakan bahwa setidaknya ada empat wacana kemajuan yang mempengaruhi perubahan budaya masyarakat di berbagai dunia termasuk di Indonesia dan Bali pada khususnya. Keempat wacana 
perubahan itu mencakup teknologi, sains, ekonomi dan sosial. Keempat wacana tersebut tidak luput mempengaruhi perubahan masyarakat dalam berkesenian. Sebagaimana muncul dan berkembangnya pertunjukan Davedan di daerah kawasan wisata Nusa Dua. Meninjau pendapat Langer dalam Danesi (2010: 233) bahwa manusia berkesenian tidaklah sebagai potongan terpisah, melainkan merupakan sebuah pengalaman emosional yang tidak lepas dari pengalaman hidup di tempat lingkungannya berada. Sebagaimana Davedan Show yang memiliki gagasan, konsep, dan tata penyajian seni budaya Nusantara namun disajikan dalam konteks pariwisata yang secara tidak langsung berimplikasi pada perubahan perspektif, ekonomi, sosial, dan budaya para pihak terkait. Perubahan struktur yang mendasar dan dominan dalam mempengaruhi desakral;isasi seni adalah kekuasaan kapitalis (Suardana, 2018).

Sebagai sebuah organisasi seni pertunjukan pariwisata Bali, Davedan Show tidak hanya berkutat pada ranah seni tradisi saja, tetapi dalam seni pertunjukan itu juga disajikan seni akrobatik yang disajikan melayang-layang di udara dengan menggunakan property tali sling. Dengan berlandaskan konsep mabayah, maka pihak produser memproduksi seni pertunjukan itu betul-betul maksimal. Setiap seniman diwajibkan tampil secara profesional. Tidak saja dalam hal teknik, penampilan pisikpun tidak luput dari perhatian. Seluruh penari diwajibkan menjaga pisik dengan selalu berlatih, menjaga pola makan, dan berat badan dengan standarisi tertentu sesuai perannya dalam pertunjukan. Dengan adanya apresiasi penonton maka para pihak terkait menjadi bersemangat untuk merepresentasikan keterampilannya dalam berkesenian.

Sebuah aktivitas seni yang berorientasi ekonomi akan berimplikasi terhadap bentuk dan kualitas produk. Potensi berkesenian yang tadinya hanya sekadar dipergunakan untuk hobby kini telah berkembang merambah pasar hiburan pada ranah pariwisata. Sebagaimana yang ditujukan oleh Davedan Show di Nusa Dua, Bali. Model pertunjukan Davedan Show memberikan nuansa baru dalam pertunjukan pariwisata di Bali. Sebelumnya, individu yang belum tergabung dalam manajemen seni tersebut berkesenian hanya sebatas wahana menyalurkan hobby sehingga segala biaya yang diperlukan untuk merawat dan mempertahankan kelompok itu harus mereka pikul sendiri.

Davedan Show yang menampilkan tema Treasure of The Archipelago itu merupakan konsep baru dalam seni pertunjukan pariwisata di Bali. Komposisi baru dalam pertunjukan itu merupakan respon produser terhadap keinginan pasar akan hiburan bernuansa baru, efisien, kompetitif dan memiliki alokasi budget lebih murah di tengah pasar pariwisata. Selain itu, Davedan Show yang memiliki karakter seni budaya Nusantara sangat strategis untuk meraih konformitas di daerah kawasan wisata Nusa Dua. Pencapaian kesejahteraan melalui pementasan tersebut telah dirasakan oleh para pihak (multiplayer effect). Terbukanya peluang kerja bagi masyarakat setempat untuk mencoba peruntungan rezeki melalui berbagai usaha dagang seperti menjual makanan, foto, dan berbagai hasil kerajinan Bali.

Secara mendasar, Davedan Show telah berkontribusi terhadap peningkatan prestise sosial masyarakat terkait di samping adanya penghargaan berupa finansial bagi peningkatan kesejahteraan hidup seniman. Kualitas dan konformitas Davedan Show menjadikan kesenian tersebut diperebutkan di ruang publik yang oleh masyarakat, wisatawan, dan para pelaku bisnis. Davedan Show memiliki kans sebagai sebuah model ikon publik di tengah pertarungan dan perebutan berbagai bentuk kekuasaan dan kepentingan di ranah pariwisata. Pada pergulatan semacam itu secara politis kreativitas Davedan Show bermakna lebih kepada membangun kesadaran baru akan perbedaan dan pluralitas makna di tengah arus perubahan sosial dengan mengadaptasikan sejumlah kearifan lokal yang masih relevan untuk menghadapi tantangan zaman kekinian.

Davedan Show pada hakekatnya berfungsi sebagai hiburan bagi penonton dalam konteks pariwisata. Penonton dalam konteks itu berperan sebagai penyeimbang pertunjukan dan penikmat sekaligus penerima informasi pertunjukan. Dalam Davedan Show, penonton dan seniman memiliki hubungan timbal balik. Pada suatu adegan pertunjukan sang seniman akan sangat puas apabila sajian pertunjukannya itu bisa membuat penonton merasa senang. Penonton yang menikmati pertunjukanpun bertujuan untuk memperoleh kepuasan batin. Ketika penonton turut berpartisipasi menari dalam pertunjukan itu manifestasi rasa kenikmatan itu dapat menjadi salah satu tinjauan kualitas Davedan Show. Beberapa bagian dari seni pertunjukan yang ditampilkan memiliki corak tersendiri dan khas sehingga menjadi sesuatu yang baru bagi para penonton. Totalitas penyajian Davedan Show itu mampu memikat hati penonton karena komposisi pertunjukan yang disajikan dalam konsep baru tersebut mampu membangkitkan gairah penonton. Dalam kaitan itu, Shohat dan Stam dalam Smiers (2009:5) menyatakan bahwa seni merupakan medan tempur simbolik karena dapat merawat, menambah maupun merubah kesadaran penonton secara individu maupun kelompok. Terwujudnya Davedan Show merupakan bagian dari perjuangan sosial para penari untuk menjaga, merawat, mendukung bahkan mencintai seni budaya beserta kearifan-kearifan lokal daerah Nusantara. Hal itu berkontribusi secara ganda terhadap sang pencipta dan para seniman pertunjukan tersebut. Pertama, suksesi sebagai penanggung jawab artistik. Kedua, suksesi terhadap peningkatan popularitas senimannya di mata penonton. Ketiga, berimplikasi terhadap penguatan relasi sosial di antara pihak terkait. Keempat, popularitas Davedan Show berimplikasi terhadap kebanggan para pihak terkait terhadap seni pertunjukan yang dimilikinya.

Davedan Show mengandung sifat multikompleks yang melukiskan nilai-nilai hakekat hidup dengan alam semesta 
dalam pola pagelaran disertai tema seni budaya Nusantara yang khas. Salah satu komponen yang tereduksi adalah nilai-nilai falsafah etis yang pada dasarnya ditujukkan untuk melembagakan pola-pola keteraturan, keseimbangan ideologis, dan kekuasaan yang menjadi identitas khas daerahnya. Setiap masyarakat memiliki nilai-nilai falsafah sebagai pedoman dalam kehidupannya. Nilai-nilai falsafah yang dilembagakan melalui cerita dan perilaku tokoh-tokoh utama di setiap daerah di Indonesia disajikan dalam Davedan Show sehingga pertunjukan itu bukan hanya sekedar tontonan melainkan juga mengandung tuntunan.

Kemunculan Davedan Show di Nusa Dua secara tidak langsung telah berimplikasi terhadap perubahan citra pertunjukan pariwisata di Bali. Melalui Davedan Show, sang pencipta menyuarakan nilai-nilai, norma-norma yang terdapat di setiap daerah di Indonesia. Melalui Davedan Show pelembagaan normatif kultural di masyarakat disosialisasikan. Davedan Show yang disajikan dalam konsep baru seolah mampu membentuk citra tersendiri. Suguhan gaya baru produk seni itu mampu memberi berkontribusi terhadap citra pertunjukan pariwisata di Nusa Dua, Bali. Menurut Fraiere dalam Sachari (2002:103) bahwa terdapat tiga tahapan kesadaran yaitu kesadaran magis, kesadaran naïf dan kesadaran kritis.

Sehubungan dengan Davedan Show terdapat kesadaran kritis dan kesadaran magis sekaligus. Selain sebagai prestise sosial, animo para seniman di daerah kawasan wisata Nusa Dua pun meningkat dalam berkesenian. Hal itu secara tidak langsung dapat mengantarkannya keluar dari ketidakberdayaan mereka berkesenian dalam konteks pariwisata, medobrak stigma ketidakmampuan masyarakat lokal untuk terlibat dalam pertunjukan modern untuk pariwisata. Setiap pelaku tampak serius dalam berkesenian. Hal ini membuat setiap pertunjukan Davedan Show sukses. Hal itu tentu saja secara tidak langsung akan berimplikasi terhadap terpeliharanya animo masyarakat di Nusa Dua Bali untuk terus melestarikan seni budayanya, membangun dan merawat rasa humanismenya untuk tetap kokoh menjadi diri sendiri di tengah dinamika kehidupan pariwisata.

\section{SIMPULAN DAN SARAN}

Berdasarka uraian di atas dapat disimpulkan bahwa : (1) Sebagai sebuah seni pertunjukan pariwisata baru, Davedan Show disajikan dengan gagasan baru, konsep penyajian baru dalam bentuk oratorium dengan menggunakan dialog bahasa Inggis. Davedan Show disajikan dengan struktur pertunjukan : seni budaya Bali, Sumatra, Sunda, Solo, Kalimantan, dan Papua. Seni Budaya daerah Nusantara yang disajikan secara medley, berkelanjutan itu diiringi musik rekaman berupa casset, dilatari properti bangunan, dan film tentang suasana alam daerah-daerah setempat; (2) Daveda Show banyak diminati wisatawan karena pertunjukan itu dilatari oleh adanya ideologi pasar, ideologi estetika, dan ideologi pelestarian budaya Nusantara; (3)
Hingga kini pertunjukan Davedan Show terus berkembang secara berkelanjutan di Amphi Theatre Nusa Dua Bali karena berimplikasi positif bagi ekonomi pelaku, para pihak terkait, pengayaan pada seni pertunjukan daerah Bali, dan sebagai identitas kawasan wisata Nusa Dua, Bali.

Berdasarkan temuan tersebut disarankan kepada masyarakat, para pihak terkait di kawasan wisata Nusa Dua, Bali agar tetap menjaga kelestarian seni pertunjukan tersebut. Hal itu dapat dilakukan baik secara teoritis maupun praktis. Secara teoritis, disarankan agar terus mengkaji, menelaah nilai-nilai budaya yang terdapat pada seni-seni budaya daerah yang ada di Indonesia sebagai pengayaan seni pertunjukan di daerah tersebut. Secara praktis di masing-masing daerah di Indonesia diharapkan terus melakukan revitalisasi budaya dalam rangka penguatan terhadap seni budaya daerahnya masing-masing dalam rangka pelestarian unsur-unsur budaya lokal di era global.

\section{DAFTAR PUSTAKA}

Atmadja, Nengah Bawa. 2010. Komodifikasi Tubuh Perempuan Joged "Ngebor" Bali. Denpasar : Prog.Studi Magister dan Doktor Kajian Budaya Universitas Udayana dan Pustaka Larasan.

Bandem, I Madé and de Boer, F.E. 1995. Balinese dance in transition. Kuala Lumpur: Oxford University Press. (An important historical and general overview of dance and drama).

Chan, Kanizar, 2014. Membaca Seni Pertunjukan Membingkai Etnoestetika. Padang : Andalas Universitas.

Coast, J. 2004. Dancing out of Bali. Singapore: Periplus. (An account of the famous Balinese tour of the UK and USA in the early 1950 s by the impresario, which gives a wonderful insight into the history and complexities of Balinese dance in the mid-twentieth century).

Coldiron Savarese, N. 2001. Antonin Artaud sees Balinese theatre at the Paris Colonial Exposition. The drama review 45, 3: 51-77. (An analysis of Artaud's encounter with Balinese dance.)

Coldiron, M. 2004. Trance and transformation of the actor in Japanese Noh and Balinese masked dance-drama. Lampeter: Edwin Mellen Press. (An advanced account of masked dance in Bali).

de Boer, F. 1996. Two modern Balinese theatre genres: Sendratari and Drama Gong. In Being modern in Bali: image and change . ed. A. Vickers, New Haven: Yale University South East Asia series, No 43. 158-178. (A review of two modern theatre forms in Bali.) 
de Zoete, B. and Spies, W. 1938. Dance and drama in Bali. London: Faber and Faber. (This is the classic work on the topic, which remains an invaluable source, even if a romanticized account.)

Dibia, I. W. and Ballinger, R. 2004. Balinese dance, drama and music: a guide to the performing arts of Bali. Periplus: Singapore. (The best introduction to the topic, with excellent photographs and text which explains drama and dance as Balinese themselves understand them.)

Fischer, J. \& Cooper, T. 1998. The folk art of Bali: the narrative tradition. New York: Oxford Univ. Press. (A good introduction to Balinese art.)

Fitzgerald, J., 1966. Peirce's Theory of Signs as a Foundation for Pragmatism. The Hague : Mouton.

Geertz, H. 2004. The life of a Balinese temple: artistry, imagination, and the history of a peasant village. Honolulu: Univ. of Hawai'i Press. (A wonderful account of how Balinese religion is intricately woven into arts and daily life.)

Gold, L. 2004. Music in Bali: experiencing music, expressing culture. Oxford: Univ. Press. (A sympathetic account of Balinese music and its links to Balinese culture, with CD.)

Hall, Stuart. 1997. Representation : Cultural representations and sinifying, pratices. London Oaks, California : Sage in associations with the Open University.

Herbst, E. 1997. Voices in Bali: energies and perceptions in vocal music and dance theater. Hanover, NH.: Univ. Press of New England. (An advanced work on the important but neglected topic of Balinese singing.)

Hitchcock, M. and Norris, L. 1995. Bali, the imaginary museum: the photographs of Walter Spies and Beryl de Zoete. Kuala Lumpur: Oxford University Press. (An introduction to the work and imagination of the authors of Dance and drama in Bali.)

Hobart, A. 1987. Dancing shadows of Bali: theatre and myth. London \& New York: KPI. (A good introduction to the different aspects of Balinese shadow theatre.)

Hobart, M. 2007. Rethinking Balinese dance. in M. Cohen, A. Lopez y Royo and L. Nozlopy, Indonesian performing arts in a transnational context, special issue of Indonesia and the Malay World, 35: 107-28. (A critical analysis of how Westerners have imagined drama and dance in Bali.)

Picard, M, 1992. Bali, Pariwisata Budaya dan Budaya Pariwisata. Jakarta Selatan : KPG (Kepustakaan Popular Gramedia)
Ruastiti, Ni Made. 2005. Seni Pertunjukan Bali Dalam Kemasan Pariwisata. Denpasar: Bali Mangsi Press.

Sanderson, Stephen K. 1993. Macrosociology Social. An Introduction to Human Societes $4^{\text {th }}$ ed. New York : Lognan Slattum, J. \& Schraub, P. 2003. Balinese masks: spirits of an ancient drama. Hong Kong: Periplus. (A lavishly illustrated account of masked dance in Bali.)

Suardana, Gede. 2018. Analisis Komodifikasi Seni Pertunjukan Pariwisata Bali Agung- The Legend Of Balinese Goddesses (Disertasi). Denpasar : Fakultas Ilmu Budaya Universitas Udayana.

Spradley J., 1972. Foundations of Cultureal Knowlage, in Spadey, P (ed) Culture and Cognition: Maps and Plans, Chanler Publishing Co., Sanfransisco.

Suwariyanti, Ida Ayu Made. 2014. Tari Rejang Lilit Dalam Upacara Dewa Yadnya Di Pura Kayangan Tiga, Desa Adat Mundeh, Tabanan. Denpasar: Institut Seni Indonesia Denpasar.

Tenzer, M. 1991. Balinese music. Berkeley, Ca.: Periplus. (A good introduction to Balinese music.)

Toffler, Alvin. 2002. Menciptakan Peradaban Baru, Politik Gelombang Ketiga/ Alvin dan Heidi Toffler. Yogyakarta: Ikon Teralitera.

Vickers, A. 1989. Bali: a paradise created. Ringwood, Victoria: Penguin. (An excellent historical analysis of how Europeans set about imagining Bali.) 